\title{
Fat embolism in infancy after intravenous fat infusions
}

\author{
A. J. BARSON, MALCOLM L. CHISWICK, AND CAROLINE M. DOIG
}

From the Department of Pathology, Special Care Baby Unit, and the Regional Neonatal Surgical Unit, St Mary's Hospital, Manchester

SUMMARY Four cases of fat embolism are described in infants receiving prolonged intravenous infusion of fat (Intralipid 20\%). This therapeutic complication has been termed 'fat overloading syndrome' but bears a clinical similarity to post-traumatic fat embolism. These 4 cases are the first to be recorded in infancy, and with histopathological proof of fat embolism. Transient high rates of infusion of Intralipid appears to be a factor in the aetiology of the condition.

Intravenous administration of emulsified lipid to supplement the caloric requirements of infants with nutritional deficiencies was used over 40 years ago (Holt et al., 1935). It then became an essential component of regimens for the complete parenteral nutrition of the sick child (Helfrick and Abelson, 1944). Clinical situations in which intravenous fat emulsions are a useful adjunct to therapy arise most frequently outside paediatrics and most published reports relate to experience with adult patients.

Serious adverse reactions are comparatively rare. Johnson et al. (1952) reported that the most common reaction was a rise in temperature which returned to normal within 4 to 8 hours of starting the infusion, accompanied occasionally by anorexia, nausea, vomiting, diarrhoea, and headache. However, these authors were the first to document a decreased platelet count and a prolonged bleeding time in 4 adults receiving 3 to $4 \mathrm{~g}$ fat $/ \mathrm{kg}$ per day for up to 11 days. Subsequently fever, jaundice, and hepatomegaly were described in a patient after receiving parenteral fat for 25 consecutive days (Watkin, 1957), and anaemia, fever, vomiting, and abdominal pain were produced in 2 healthy volunteers after 4 weeks of intravenous lipid (Levenson et al., 1957).

The adverse reactions following prolonged intravenous fat therapy came to be known as 'fat overloading syndrome', and it was not until 1961 that attention was drawn to the clinical similarity of this phenomenon to post-traumatic fat embolism (Alexander and Zieve, 1961). The hypothesis that pulmonary fat embolism might result from longterm parenteral lipid has recently received further support from cases reported by Horisberger (1966),

Received 22 August 1977
Goulon et al. (1974), and Guignier et al. (1975) where a 'snowstorm' appearance of the chest $x$-ray coincided with the clinical symptoms. There has been one previous account of this in a 10-year-old boy (Födisch et al., 1972). The 4 cases we report are the first observed in infancy and the only cases where the presence of pulmonary fat embolism has been substantiated by histopathology.

\section{Case reports}

All 4 infants were treated at this hospital between 1975 to 1977, and all at some stage during their illness received total parenteral nutrition consisting of a mixture of $20 \%$ Intralipid*, Vamin-glucose*, $10 \%$ dextrose, electrolytes, and vitamins according to the regimen summarised by Panter-Brick (1976). Details of the fat intake of the 4 babies are shown in the Table.

Case 1. Born vaginally at 34 weeks' gestation after spontaneous onset of labour; birthweight $1.63 \mathrm{~kg}$, $<$ 10th centile for gestational age (Milner and Richards, 1974). Pregnancy had been complicated by pre-eclamptic toxaemia. The baby required

*Kabi-Vitrum Ltd, Stockholm, Sweden.

Table Details of intravenous fat (Intralipid 20\%) administration in 4 patients

\begin{tabular}{|c|c|c|c|c|}
\hline & Case 1 & Case 2 & Case 3 & Case 4 \\
\hline $\begin{array}{l}\text { +Body weight }(\mathbf{k g}) \\
\text { Mean rate of fat }\end{array}$ & $1 \cdot 65$ & $1 \cdot 48$ & $2 \cdot 76$ & $3 \cdot 13$ \\
\hline administration ( $\mathrm{g} / \mathrm{kg}$ per $\mathrm{h}$ ) & 0.14 & $0 \cdot 15$ & 0.08 & $0 \cdot 15$ \\
\hline $\begin{array}{l}\text { Total duration of therapy } \\
\text { (d) } \\
\text { Maximum rate of fat }\end{array}$ & 11 & 14 & 12 & 18 \\
\hline administration $(\mathrm{g} / \mathrm{kg}$ per $\mathrm{h})$ & $0 \cdot 18$ & $0 \cdot 27$ & 0.51 & 0.70 \\
\hline
\end{tabular}


intermittent positive pressure ventilation by face mask for 3 minutes after birth before respirations were established.

During the first 24 hours total fluid intake was $90 \mathrm{ml} / \mathrm{kg}$, half of this given as $10 \%$ dextrose via a peripheral vein infusion, the remainder given as milk (SMA Goldcap, Wyeth Ltd) through a nasogastric tube. She became intolerant of milk feeds at 48 hours, and developed abdominal distension and an unstable rectal temperature. Abdominal $x$-ray showed intestinal intramural gas consistent with the occurrence of necrotising enterocolitis. Milk feeds were stopped and an intravenous solution of $1 / 5$ isotonic saline in $10 \%$ dextrose at a rate of $120 \mathrm{ml} / \mathrm{kg}$ per 24 hours increasing to $150 \mathrm{ml} / \mathrm{kg}$ on day 4 was substituted. Intramuscular penicillin and gentamicin were started. The abdominal distension was less

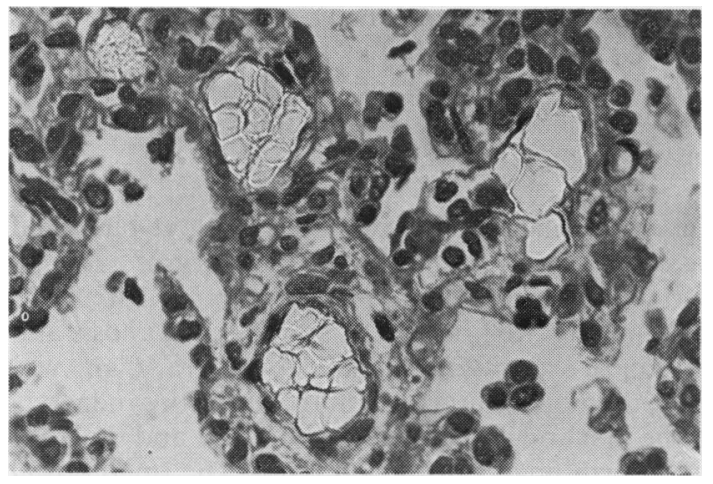

Fig. 1 Case 1. Refractile globules of unstained fat blocking capillaries in the periphery of the lung. ( $H$ and $E . \times 175$.) marked by the 7th day and the intramural gas was no longer visible on abdominal $x$-ray, but the stools had become blood stained. Total parenteral nutrition, which included $20 \%$ Intralipid was begun using a superficial peripheral vein for the infusion site. Abdominal distension disappeared by day 14, and nasogastric feeds of human milk were introduced at $1 \mathrm{ml} / \mathrm{h}$ increasing to $3 \mathrm{ml} / \mathrm{h}$ on day 16 . On day 17 , while still receiving intravenous nutrition $(150 \mathrm{ml} / \mathrm{kg}$ per day), she suddenly suffered a cardiac arrest and could not be resuscitated. Intralipid had been given for 11 days preceding death. Haemoglobin had fallen from 13.8 to $6 \mathrm{~g} / \mathrm{dl}$ during the previous 2 days.

At necropsy the most striking feature was a concavity of the right temporal lobe where the underlying white matter was softened and atrophic. The CSF was xanthochromic. Both pleural cavities contained an effusion of turbid yellow fluid and numerous petechiae were scattered throughout both lungs. Microscopically many intravascular plugs of lipid were visible predominantly in the peripheral regions of the lungs. On paraffin-blocked tissue these plugs often had a bubbly refractile appearance (Fig. 1.) Elsewhere, although the capillaries were apparently empty, they were unnaturally distended and circular for vessels seen after death. That such vessels contained fat emboli was shown by specific stains for fat on frozen sections prepared from wet formalin-fixed tissue (Fig. 2). Many of the alveolae contained fat-laden macrophages. No intravascular fat was seen in any other organ apart from a single vessel within the spleen. Sections of the softened area of the temporal lobe confirmed the gross impression of an organising infarction. A microglial

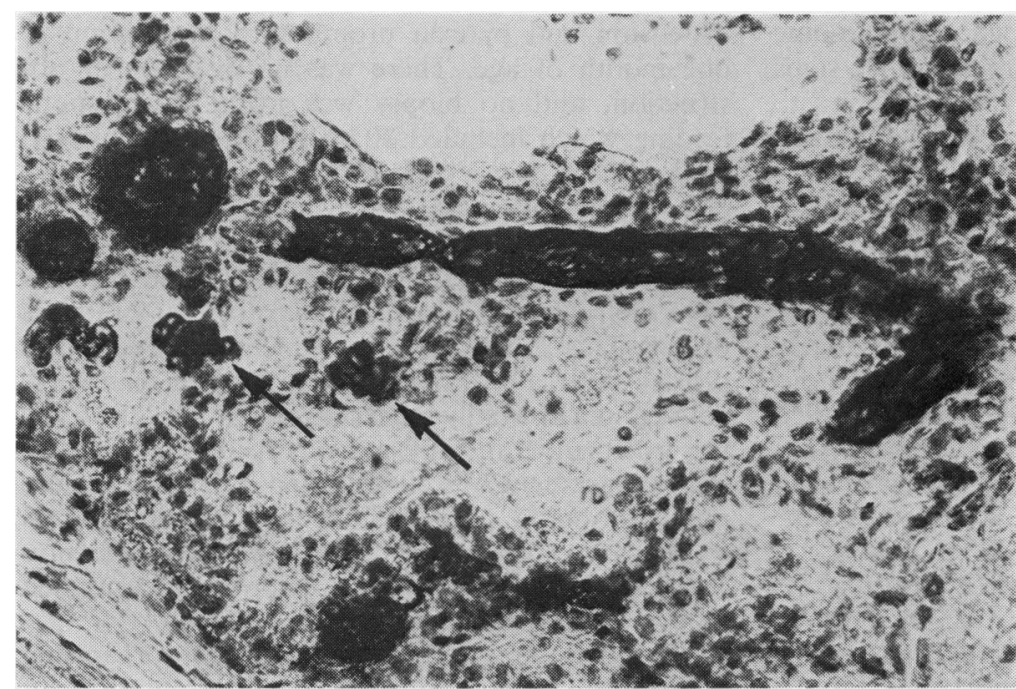

Fig. 2 Case 1. Frozen section of lung stained to show fat emboli within three capillaries cut transversely and one longitudinally. Arrows show lipid-laden alveolar macrophages. (Oil Red O. $\times 170$.) 
response and focal calcification was seen but there was no evidence of intravascular lipid on frozen sections. Microscopically the small intestine displayed an organising peritonitis compatible with the clinical impression of a convalescing necrotising enterocolitis.

Case 2. Born vaginally after spontaneous onset of labour at 27 weeks' gestation; birthweight $0.93 \mathrm{~kg}$, by extrapolation on the 25th centile for gestational age (Milner and Richards, 1974). Intermittent vaginal bleeding had occurred during the last week of pregnancy. He gasped immediately after birth and had a heart rate of $40 / \mathrm{min}$. Spontaneous respirations and a heart rate of $140 / \mathrm{min}$ were established at 5 minutes.

Intrajejunal milk feeds (SMA Gold Cap, Wyeth Ltd.) were started soon after birth and by the 5th day he was tolerating $180 \mathrm{ml} / \mathrm{kg}$. Nasogastric feeding was gradually substituted during the $3 \mathrm{rd}$ and 4 th week and by the 5 th week he was tolerating 200 $\mathrm{ml} / \mathrm{kg}$ per day of milk via a nasogastric tube,

He developed abdominal distension, bile-stained vomiting, and passed bloody stools during the 6th week. Nasogastric feeding was stopped and total parenteral nutrition which included $20 \%$ Intralipid was begun via a superficial vein. A plain abdominal $x$-ray suggested the presence of mucosal oedema in the small bowel and a provisional diagnosis of necrotising enterocolitis was made. A pathogenic coliform organism $(E$. coli, O18) was subsequently isolated from the stools. The abdominal distension improved during the 7th week but he suffered several prolonged apnoeic spells that culminated in the need for mechanical ventilation. Total parenteral nutrition was continued but after several days of ventilatory support he developed troublesome bleeding from several venepuncture sites and signs of circulatory failure.

He died at 54 days of age having been maintained for 14 days on intravenous fluids terminally. Necropsy examination showed firm, well localised subarachnoid haematomata over both occipital lobes and the left parietal region of the kind seen typically with disseminated intravascular coagulopathy, and a small right-sided intraventricular haemorrhage. Numerous petechiae were seen throughout the lungs and multiple peripheral fat emboli were identified within them microscopically. Fat-laden macrophages were present in some of the alveoli. No fat emboli were seen in other organs.

Case 3. Born by caesarean section for fetal distress after a term pregnancy. He weighed $3.3 \mathrm{~kg}$ and was observed to have anorectal agenesis with passage of meconium from the urethera. Laparotomy on the day after birth showed a high type of rectal atresia with a hugely distended colon associated with a fistulous communication into the urinary system. Both kidneys were enlarged and cystic with a hydroureter on the left side. Despite a colostomy, intestinal obstruction required resection of gangrenous small bowel on day 4. Intravenous feeding, including $20 \%$ Intralipid via a superficial vein, was begun on day 8 . During the next 10 days $\mathrm{Hb}$ fell to $7 \cdot 7 \mathrm{~g} / \mathrm{dl}$ and a bowel fistula developed adjacent to the abdominal wound. There was excessive loss of urinary sodium, and blood urea rose to $16.6 \mathrm{mg}$ / $100 \mathrm{ml}(2.8 \mathrm{mmol} / \mathrm{l})$. Intravenous feeding was stopped 6 days before he died. Parenteral nutrition had been given for 12 complete days during a 16-day period.

In addition to the renal and intestinal malformations seen at laparotomy, necropsy examination showed a widespread peritonitis and meningitis due to $E$. coli type I. Fat stains showed multiple lipid emboli, predominantly in the peripheral regions of both lungs. Fat emboli were not seen in any other organs.

Case 4. A male infant weighed $2.9 \mathrm{~kg}$ at birth and was admitted at 18 days with a history of cyanosis during feeding and episodes of abdominal distension. He appeared well but had a peripheral cyanosis and an apical systolic murmur. An extra digit was present on both hands and both feet, with syndactyly of the first and second toes of both feet and the third and fourth fingers of the left hand. The small bowel was minimally distended but he had loose, foul smelling stools. Hirschsprung's disease was suspected but not confirmed by a rectal punch biopsy. The diarrhoea continued and an episode of abdominal distension and pyrexia prompted a laparotomy at one month of age. There was no evidence of obstruction, and no biopsy was taken. Intravenous feeding which included $20 \%$ Intralipid was started during the fifth week of life. He continued to have episodes of abdominal distension with large gastric aspirates and loose stools. A second rectal biopsy was seen to be aganglionic and multiple biopsies were then taken at a further laparotomy at 2 months of age. This showed a long-segment Hirschsprung's disease with a transitional area in the transverse colon and a normally innervated ileum. A colostomy was performed and intravenous feeding continued, but management was complicated by cardiac failure and continuing peritoneal sepsis. He died at 13 weeks having received 18 days of parenteral nutrition over a period of 47 days. Intralipid was discontinued 4 days before death.

Necropsy showed a generalised but organising peritonitis. There was a large atrial septal defect 
but no other cardiac malformation. Both pleural cavities contained yellow fluid and focal haemorrhages were present throughout both lungs. This was confirmed microscopically, and numerous peripheral lipid emboli and fat laden alveolar macrophages were shown. No fat emboli were identified outside the lungs.

\section{Discussion}

Commercial fat emulsions for intravenous nutrition consist of vegetable oil, either cottonseed or soyabean oil, emulsified in distilled water with a stabilising agent such as phospholipid or lecithin. Intralipid $20 \%$ used in the treatment of our cases is composed of $200 \mathrm{~g}$ soyabean oil stabilised with purified eggyolk phospholipids with $25 \mathrm{~g}$ glycerol to obtain isotonicity with blood when the whole is made up to $1000 \mathrm{ml}$ with distilled water.

Acute toxic effects with modern preparations are rare and of little clinical consequence, only $1.7 \%$ having febrile reactions (Schindel, 1975). Since in clinical practice fat emulsions are often given over a long period, the adverse effects of prolonged administration are important. Experimental evidence indicates that there are considerable biological differences between the various emulsions in this respect. Wretlind (1972) cites an experiment in which a group of dogs received $9 \mathrm{~g}$ fat $/ \mathrm{kg}$ per day intravenously for 4 weeks without untoward reactions when this was given as Intralipid, whereas other commercial emulsions produced severe toxic effects. Deaths resulted from fat embolism, internal bleeding, and liver damage. Unlike other preparations Intralipid infusion does not result in the accumulation of fat in the Kupffer cells of the liver, and this was confirmed in our study. However, Gigon et al. (1966) have shown that in man Intralipid is taken up by the endothelial cells of the lung, although no aggregation of fat particles was seen. It has been alleged (Solassol et al., 1974) that the risk of 'fat overloading syndrome' is significantly less with soyabean oil and egg phospholipid used in Intralipid than with cottonseed oil and soyabean lecithin. Nevertheless, 2 of the dozen recorded cases have appeared to result from Intralipid (Horisberger, 1966; Guignier et al., 1975).

The pathogenesis of symptoms from the longterm infusion of fat is far from clear. Particles of Intralipid $20 \%$ have a mean diameter of $0.16 \mu \mathrm{m}$, which lies within the normal range in size of chylomicrons $(0.096-0.21 \mu \mathrm{m})$. Experimental evidence indicates that fat particles have to be larger than $8 \mu \mathrm{m}$ for embolism to occur (Haman and Ragaz, 1950). Goulon et al. (1974) postulated that this might be brought about by the action of an antibody directed against the stabilising agent in the emulsion, but this is as yet unproven. Disseminated intravascular coagulopathy, which occurred in one of our 4 patients (Case 2), is an important concomitant feature of post-traumatic pulmonary fat embolism (Keith et al., 1971) and it is difficult to differentiate clinically between the effects of intravascular thrombus and intravascular fat. Anaemia with bleeding manifestations characterises both posttraumatic fat embolism and the fat overloading syndrome, although thrombocytopenia was not clearly shown in our cases. Recent work suggests that platelet function and aggregation are closely related to the concentration of lipid in the milieu in which they are found (Miettenen, 1974; Shattil et al., 1975).

It is probably not entirely fortuitous that the histopathological confirmation that Intralipid was capable of forming emboli should occur in infants. Most of the previous reported cases of fat overloading syndrome have been in chronically ill adults who have recovered completely once the lipid infusion was withdrawn. The 2 fatal cases reported by Födisch et al. (1972) showed an increase in plasma lipid which was sufficiently gross as to be detectable at necropsy. Some caution must be exercised in equating intravascular lipid postmortem with embolism during life. There is experimental evidence that fat globules may coalesce within blood vessels after death (Allerdyce, 1971). However, in our cases the peripheral distribution of emboli entirely within small pulmonary vessels which were rounded and distended by their contents makes post-mortem artefactual explanation unlikely. The presence of lipid-laden macrophages within the alveolar spaces also supports the view that fat embolism took place at a finite interval before death. Even in the absence of demonstrable cerebral intravascular fat in Case 1 , there was no other acceptable explanation for the focus of cerebral softening. The histology of the cerebral infarction suggested a paradoxical embolism occurring long enough before death for intravascular fat to have been removed.

There is no way of accurately estimating the incidence of embolism complicating intravenous lipid therapy. The situation may be analogous to post-traumatic embolism in which there is pathological evidence that pulmonary fat embolism occurs in over $90 \%$ of patients with fractures though only a small proportion of these will display clinical fat embolism syndrome. Diagnosis of this syndrome in an otherwise healthy patient is usually fairly evident even in the neonatal period (Nicod, 1938). Difficulty arises when an infant is so profoundly ill that symptoms produced by the 
intravenous fat are confused with those of the disease being treated, as in 3 infants in this report. One had peritonitis, meningitis, and cystic kidneys; another died of peritonitis and congenital heart disease; and a third had cerebral haemorrhage. Only one (Case 1) died unexpectedly. The lack of an obvious explanation for the terminal collapse, profound drop in $\mathrm{Hb}$ concentration, pyrexia with a sterile blood culture, and focal cerebral softening prompted a more careful examination of the necropsy material. Having demonstrated intravascular lipid, the other 3 cases only came to light from a specific search of postmortem material retrospectively. It is notable that Intralipid emboli are more refractile in paraffinblocked material than post-traumatic fat emboli (Fig. 1) but they are vividly illustrated with fatstained frozen sections (Fig. 2).

There are good published accounts of posttraumatic fat embolism in children (Weisz et al., 1973). Weisz et al. (1974) list ten minor signs on which to base a diagnosis, keeping in mind children on long-term Intralipid infusion: hypoxia, pyrexia; tachycardia; anaemia; thrombocytopenia (with or without coagulopathy); petechiae; fat excretion in urine or sputum; changes in fat metabolism (fat macroglobulinaemia, raised serum lipase, lipid electrophoretic changes); 'snowstorm' chest $x$-ray and neurological abnormalities such as paresis, coma, and electroencephalographic changes. Hypoxaemia is an early sign and the similarity to idiopathic respiratory distress syndrome is well recognised (Ashbaugh et al., 1967; Burgher et al., 1974). Diagnosis of fat embolism can only be made with certainty during life by the detection of retinal fat embolism or from biopsy. Without specific stains it may easily pass unrecognised at necropsy.

Gustafson et al. (1974) measured plasma lipids in low birthweight babies after repeated intravenous injections of Intralipid and showed that a dose equivalent to $0.15 \mathrm{~g}$ fat $\% \mathrm{~kg}$ birthweight per hour was well tolerated in preterm babies of appropriate weight for gestational age. However, the same dose caused an accumulation of lipids in the plasma of light-for-dates babies. Wretlind (1972) recommended that for neonates and infants the rate of Intralipid infusion should not exceed $0.17 \mathrm{~g}$ fat $/ \mathrm{kg}$ per hour. Case 1, a low-birthweight baby who was both preterm and light-for-dates received $0.18 \mathrm{~g}$ fat $/ \mathrm{kg}$ per hour during one 20-hour period. The lightest infant (Case 2), weighing $1.48 \mathrm{~kg}$, had a maximum of $0.27 \mathrm{~g}$ fat $/ \mathrm{kg}$ per hour. The 2 term infants (Cases 3, 4) had transient episodes when the rate of Intralipid infusion was three and four times that recommended, even though the total daily dose was within normal limits (Table). None of the infants had plasma turbidity on daily inspection.
It therefore seems wise to regulate the infusion of fat as evenly as is technically possible throughout the day. Speeding up the infusion of fat to make up a 'correct' dose for a given time period should be discouraged. Fat overloading syndrome is said to respond to high doses of steroids, and heparin may facilitate the clearance of lipid (Alexander and Zieve, 1961). Low molecular dextran has also been used with good effect (Horisberger, 1966).

\section{References}

Alexander, C. S., and Zieve, L. (1961). Fat infusions. Archives of Internal Medicine, 107, 514-528.

Allerdyce, D. E. (1971). The post-mortem interval as a factor in fat embolism. Archives of Pathology, 92, 248-253.

Ashbaugh, D. G., Bigelow, D. B., Petty, T. L., and Levine, B. E. (1967). Acute respiratory distress in adults. Lancet, 2, 319-323.

Burgher, L. W., Dines, D. E., Linscheid, R. L., and Didier, E. P. (1974). Fat embolism and the adult respiratory distress syndrome. Mayo Clinic Proceedings, 49, 107-109.

Födisch, H. J., Propst, A., and Mikuz, G. (1972). Fettüberladungssyndrom nach parenteraler Zufuhr von Lipidemulsionen. Verhandlungen der Deutschen Gesellschaft für Pathologie, 56, 431-435.

Gigon, J. P., Enderlin, F., and Scheidegger, S. (1966). Über das Schicksal infundierter Fettemulsionen in der menschlichen Lunge. Schweizerische Medizinische Wochenscrift, 96, 71-75.

Goulon, M., Barois, A., Grosbuis, S., and Schortgen, G. (1974). Embolie graisseuse après perfusions répétées d'émulsions lipidiques. La Nouvelle Presse Médicale, 3, 13-18.

Guignier, M., Hernandez, J. L., Pircher, C., Muller, J. M., Morena, H., Guidicelli, H., and Banon, F. (1975). Un cas d'embolie graisseuse au cours d'une nutrition parentérale prolongée. La Nouvelle Presse Médicale, 4, 973.

Gustafson, A., Kjellmer, I., Olegård, R., and Victorin, L. (1974). Nutrition in low birth-weight infants. II. Repeated injections of fat emulsion. Acta Paediatrica Scandinavica, 63, 177-182.

Haman, J. W., and Ragaz, F. J. (1950). The pathogenesis of experimental fat embolism. American Journal of Pathology, 26, 551-563.

Helfrick, F. W., and Abelson, N. M. (1944). Intravenous feeding of a complete diet in a child. Journal of Pediatrics, 25, $400-403$.

Holt, L. E., Tidwell, H. C., and Scott, T. F. M. (1935). The intravenous administration of fat. Journal of Pediatrics, 6, 151-160.

Horisberger, B. (1966). Schwere pulmonale und cerebrale Zirkulationsstörungen nach hochdosierter parenteraler Zufuhr einer Fettemulsion. Ein Fall einer aussergewöhnlichen therapeutischen komplikation. Schweizerische Medizinische Wochenscrift, 96, 1065-1069.

Johnson, W. A., Freeman, S., and Meyer, K. A. (1952). Some effects of intravenous fat emulsions on human subjects. Journal of Laboratory and Clinical Medicine, 39, 176-183.

Keith, R. G., Mahoney, L. J., and Garvey, M. B. (1971). Disseminated intravascular coagulation: an important feature of the fat embolism syndrome. Canadian Medical Association Journal, 105, 74-76.

Levenson, M. S., Upjohn, H. L., and Sheehy, T. H. (1957). Two severe reactions following the long term infusion of large amounts of intravenous fat emulsion. Metabolism, 6, 807-814. 
Miettinen, T. A. (1974). Hyperlipoproteinemia-relation to platelet lipids, platelet function and tendency to thrombosis. Thrombosis Research, 4, Suppl., 41-47.

Milner, R. D. G., and Richards, B. (1974). An analysis of birth weight by gestational age of infants born in England and Wales, 1967 to 1971. Journal of Obstetrics and Gynaecology of the British Commonwealth, 81, 956-967.

Nicod, J. L. (1938). Embolie graisseuse chez le nouveau-né. Schweizerische Medizinische Wochenscrift, 68, 845-846.

Panter-Brick, M. (1976). Intravenous nutrition of babies and infants. European Journal of Intensive Care Medicine, 2, 45-51.

Schindel, L. (1975). Meyler's Side Effects of Drugs, Vol. 8, pp. 738-763. Ed. by M. N. G. Dukes. Excepta Medica, Amsterdam.

Shattil, S. J., Anaya-Galindo, R., Bennett, J., Colman, R. W., and Cooper, R. A. (1975). Platelet hypersensitivity induced by cholesterol incorporation. Journal of Clinical Investigation, 55, 636-643.

Solassol, C., Joyeux, H., Pujol, H. and Romieu, C. (1974). Prevention de l'embolie graisseuse en nutrition parentérale prolongée. Choix đe l'emulsion lipidique. La Nouvelle Presse Médicale, 3, 528.

Watkin, D. M. (1957). Clinical, chemical, hematologic and anatomic changes accompanying the repeated intravenous administration of fat emulsion to man. Metabolism, 6, 785-806.

Weisz, G. M., Rang, M., and Salter, R. B. (1973). Posttraumatic fat embolism in children. Journal of Trauma, 13, 529-534.

Weisz, G. M., Schramek, A., Abrahanson, J., and Barzilai, A. (1974). Fat embolism in children: tests for its early detection. Journal of Pediatric Surgery, 9, 163-167.

Wretlind, A. (1972). Complete intravenous nutrition. Theoretical and experimental background. Nutrition and Metabolism, 14, Suppl., 1-57.

Correspondence to Dr A. J. Barson, Department of Pathology, St Mary's Hospital, Whitworth Park, Manchester M13 0JH. 